\title{
E-WOM and Its Impacts on Purchasing Behavior: A Comparative Study between Thai and Indonesian Millennials
}

\author{
Athapol Ruangkanjanases* \\ Chulalongkorn Business School, Chulalongkorn University, Thailand \\ athapol@cbs.chula.ac.th \\ Pasika Jeebjong \\ Chulalongkorn Business School, Chulalongkorn University, Thailand \\ pasika.jeebjong@gmail.com
}

Natalia

BINUS Business School, Bina Nusantara University, Indonesia National Taiwan University of Science and Technology, Taiwan natalia@binus.edu

Lim Sanny

BINUS Business School, Bina Nusantara University, Indonesia

Isanny@binus.edu

\begin{abstract}
Social media has become a valuable information source that creates opportunities for users to share their comments about a product or service, establishing powerful electronic Word-of-Mouth conversations that may have an impact on purchasing behavior. The study aims to 1) study consumers' perceptions towards the usefulness of electronic Word-of-Mouth with respect to three factors, i.e. online information quality, online information credibility, and consumers' attitude towards online information; 2) examine the influence of online information usefulness on online information adoption; and 3) examine the influence of online information adoption on consumers' ${ }^{6}$ purchase intentions. This study used an online survey to collect primary data from 200 Thai and 200 Indonesian millennial internet users. The result indicates a relatively distinctive result between Thai and Indonesian consumers, as Thai consumers focus mainly on their attitudes towards online information when they consider the usefulness of online information. On the other hand, Indonesian consumers focus on both their attitudes towards online information and the credibility of online information. Nonetheless, both groups share similar traits in other respects. Online information usefulness has an impact on online information adoption, while online information adoption produces a further impact on consumers' purchase intentions.
\end{abstract}

Keywords: Electronic Word-of-Mouth, eWOM, Online review, Social Media, Purchasing Behavior 


\section{INTRODUCTION}

In the digital age, digital technology is becoming more and more prevalent and widespread, and the internet has become one of the key components of people's daily habitual activities. It has, in fact, become one of the most influential media of our time. It provides users with boundless resources and information of various topics and interest, allowing people to find almost everything with just a few mouse clicks. Together with its expansion has come a rise in the growth of electronic Word-of-Mouth (eWOM). Partially acting as a form of online review shared by previous consumers, eWOM is a readily available source of information for new customers who have not had immediate experience with a certain product or service. Online customer evaluations can alter other consumers' consideration process and buying decisions, as any negative feedback may cause potential damage to a brand's reputation. [1] The popularity of social networking sites such as Facebook, Twitter, Instagram, and Youtube further emphasizes the expansion of the eWOM, as they are available on various platforms and can be accessed by anyone who has an internet connection. This allows people to post their own opinions through any form of social media at their convenience. In fact, the consumers' opinions can be expressed via multiple forms, such as simply liking or sharing the messages they agree with. Furthermore, numerous social media platforms provide functions that allow users to include stickers, pictures, or video into their posts to endorse the visual enrichment and attract readers' attention [2]. The fact that many users are sharing their opinions without any advertising purposes draws more attention to their posts, as it indicates that readers will be provided with a reliable and honest opinion towards a brand, product or service. Nevertheless, marketers can still use social media, both explicitly and implicitly, in promoting their products or services as well. Hence, readers are required to evaluate the online information they encounter, and its source, before utilize it during the decision-making stage [3].

The objective of the present work paper is to examine the relationship between the influence of eWOM and consumers' purchase intentions, assuming that the influence of eWOM revolves around both the information and the reader. The readers will consider the information they receive from the internet prior to their purchases, yet their own attitudes and sentiments do play roles in their decisions as well. To further analyze if cultural differences have any significance in the theory, the study compares the result between Thai and Indonesian millennials, technology savvy groups aged between 17 and 39 years old. Beneath the diversity, both countries share some common roots that are reflected through culture, religion, food, and even portions of the languages. Thus, the authors find it appealing to delve deeper to see if a different result emerges between the groups from the two countries when it comes to the influence of eWOM. The authors decided to center the study on millennials, as they are quite familiar with social media and are likely to utilize these platforms in acquiring information about certain products or services when making their purchases. Additionally, the relatively younger age group within the millennial generation is entering the workforce, thus experiencing a general upswing in their purchasing power. 


\section{LITERATURE REVIEW}

\subsection{Background of Word of Mouth}

Electronic Word-of-Mouth is an interpersonal communication that has a strong influence on consumers' purchasing decisions [4], [5]. Traditional WOM doesn't only function as a source of referrals; but stretches further to include recommendations, which, in a way, reflect consumer satisfaction and loyalty towards a brand [6]. In 1991, Herr, Kardes, and Kim [7] published an article in which they stated that, compared to traditional advertisement methods such as television, radio, printed ads, or personal selling, WOM has a greater effect on information receivers. It provides rather vividly presented information, but doesn't overwhelm information receivers with extensive attributes like advertisements. The researchers thus suggested that the source of information can produce strong judgmental effects on a product. In fact, providing consumers with negative or neutral attitudes towards products and services is more effective and stimulates more purchases than providing only positive attitudes and advertising [8].

\section{2 eWOM on Social Media}

The popularity of internet and social media usage has expanded the influence of Word-of-Mouth further than ever before. It isn't limited to the traditional offline platforms or direct person-to-person communication anymore. With the widespread use of web 2.0, internet users are able to share their opinions and reviews online via written text, pictures, video or applications. The internet allows the users an enjoyable and ever-present way to read and publish their own contributions easily [3]. Later on, users are introduced to even handier consumer-opinion platforms through new social networking sites and applications such as Facebook, Twitter and Instagram. Online communication outperforms traditional communication in various ways. For instance, social media users don't need to physically be present at a certain place or at a certain time to gather information. Once uploaded, the information is kept on cloud storage, ready for to be retrieved at any time. Thus, the platforms allow users to visit websites, read, or post further comments at their convenience [9]. Additionally, online information can reach an extensive audience worldwide, and cover almost every area of consumption, using only an internet connection [10]. Certain social media platforms also grant users options to add pictures, video, animated GIFs, or hashtags (\#) for further visual enrichment, attracting more viewers.

However, Wang and Strong [11] also suggested a "fitness for use" model, explaining that the quality of each data set should be assessed differently, depending on the consumers' point of view. Thus, a set of information could be deemed highly qualified by one consumer, while being completely disregarded by another. Additionally, Kandari et al. [12] conducted further research to better identify data quality in web-based context. The result of the study identified that the data with high quality are up-to-date, accurate, and consist of sufficient information.

\subsection{Attitudes and Purchasing Behavior}


An attitude is "a relatively enduring organization of beliefs, feelings, and behavioral tendencies towards socially significant objects, groups, events or symbols" [13]. In particular, attitudes are based on an individual's trust in the source of information that leads to his or her purchase decisions.

In 2004, Schiffman and Kanuk [14] formulated a CAC Model, explaining that attitudes consist of three components; Cognitive component, Affective component, and Conative component.

\section{1) Cognitive component}

The cognitive component is an evaluation of an individual's beliefs, thoughts, attributes, and knowledge towards an attitude object without any emotional involvement. The component is commonly reflected in generalities or stereotypes.

\section{2) Affective component}

The affective component involves an individual's feelings and emotions, such as that person's like and/or dislike towards an attitude object. The component is strongly tied to the cognitive component as emotions work simultaneously with cognitive process [15].

\section{3) Conative component}

This element is an individual's verbal or nonverbal response to the attitude object, regardless of the person's relevant level of favorability.

These components shape a person's attitude, which is reflected through his or her behavior towards the attitude object. Additionally, a psychological phenomenon called the Bandwagon Effect further suggests that people adopt certain actions primarily because other people are doing the same, regardless of their own beliefs or attitudes [16]. The more people adopt that particular trend, the more other people will follow.

In terms of purchasing behavior, Munthiu [17] proposed a model to explain the complete buyer decision process. It consists of five stages and starts when a consumer recognizes a need to buy a certain product or service to fill a need; the cycle is completed with the decision to purchase (or not purchase) said product or service. During the decision process, electronic Word-of-Mouth could have an influence on consumers' decisions, as they are in search of information, and evaluating the alternatives.

Moreover, the research conducted by Xiao et al. [18] confirms that social review - user-generated contents on social networks to share their ideas, insights, experiences, and perspectives - has a positive impact on consumers' purchase intention. This is in line with the study by Poturak and Softic [19], which indicates that electronic Word-of-Mouth created by both firm-created contents and user-generated contents have an influence on brand equity, subsequently affecting consumers' purchase intentions.

\subsection{Cultural Aspects}


Hofstede [20] conducted a survey study to identify differences in national value systems, based on his observation that people were similar in all respects except nationality.

According to statistics, [21] Thais and Indonesians share some similarities in terms of power distance (the strength of societal social hierarchy), individualism, and uncertainty avoidance. The people of both countries have a high level of power distance, while their levels of individualism are low. They also tend to avoid any unknown situations. In terms of masculinity, Indonesian culture is considered to be low masculine, while the score for Thailand indicates femininity. Additionally, the two countries are quite different in terms of long-term orientation, as Thai society is more normative and more focused on quick results, whereas Indonesian society is more pragmatic, and Indonesians prepare themselves for the future. Lastly, in terms of indulgence, it is still unclear whether Thailand should be identified as indulgent or restrained, while the score of Indonesia suggests that it has a culture of restraint.

\section{Hypotheses development and research model}

\subsection{Conceptual Model}

This research will be using an adapted version of the Information Acceptance Model (IACM) [3] to study the relationship between Online Information Quality, Online Information Credibility, Consumers' Attitude towards Online Information, Online Information Usefulness, Online Information Adoption, and Purchase Intention as shown in Figure 1.

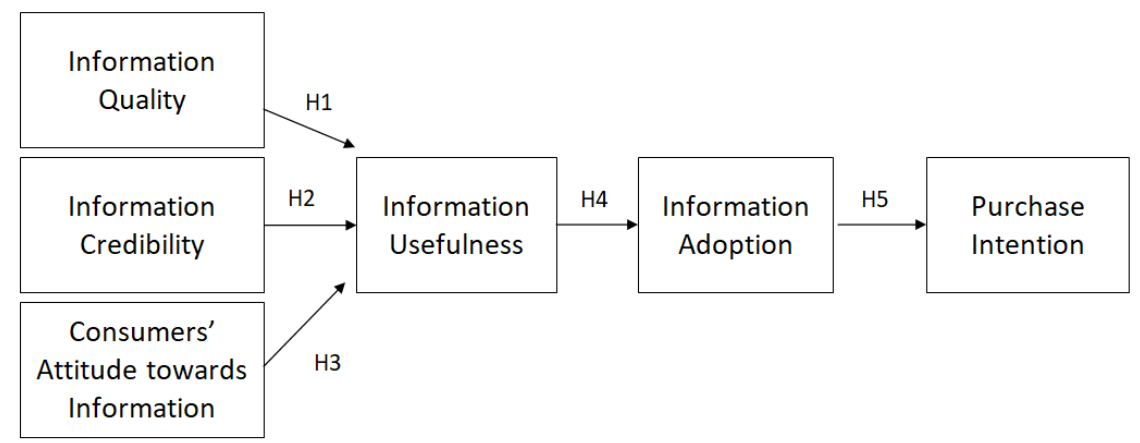

Fig. 1 Conceptual Model

\subsection{Online Information Quality}

Despite the fact that there is no formality or accepted standard in consumer online reviews, the quality of the information can be an influential aspect that recipients consider when gathering information. High-quality reviews that provide readers with relevant information in a comprehensible manner impart a greater influence than low-quality reviews that contain more emotional judgment and provide less transparency to readers. Furthermore, as the information source of the electronic Word-Of-Mouth can be an anonymous person, the quality of the content thus becomes an essential instrument in evaluating the credibility of the information itself 
[22], [23]. Therefore, the authors predict that online information quality is positively related to online information usefulness.

Hypothesis 1a: In Thai consumers' opinions, online information quality has an effect on the information's usefulness.

Hypothesis 1b: In Indonesian consumers' opinions, information quality has an effect on the information's usefulness.

\subsection{Online Information Credibility}

Perceived as being more reliable and trustworthy than company-sponsored information, the popularity of the electronic Word-Of-Mouth has increased. In consumers' opinions, eWOM is likely to provide honest opinion towards the pros and cons of a product or a service, whereas advertisements avoid mentioning weaknesses and highlight only strengths [24]. Therefore, the authors predict that online information credibility is positively related to online information usefulness.

Hypothesis 2a: In Thai consumers' opinions, online information credibility has an effect on the information's usefulness.

Hypothesis 2b: In Indonesian consumers' opinions, information credibility has an effect on the information's usefulness.

\subsection{Attitudes towards Online Information}

Almost 45 years ago, Fishbein and Ajzen [25] published a model called Theory of Reasoned Action (TRA) in which consumers' attitudes were discussed. It was found that consumers' attitudes are reflected in their responses towards the attitude object, which can drive consumers' purchasing decisions. Moreover, the attitude also has an effect on a person's evaluation of electronic Word-Of-Mouth [23]. Thus, the following hypotheses are developed to examine the relationship between one's attitude and the usefulness of online information.

Hypothesis 3a: In Thai consumers' opinions, consumers' attitudes towards online information has an effect on the information's usefulness.

Hypothesis 3b: In Indonesian consumers' opinions, consumers' attitudes towards online information has an effect on the information's usefulness.

\subsection{Online Information Usefulness}

In this conceptual model, the function of online information's usefulness is divided into two parts. During the first stage, it serves as a dependent variable that is affected by the four abovementioned independent variables. In the second stage, the variable serves as an independent variable that has an influence on the information adoption. One study by Sussman and Siegal [26] reported that information's usefulness is positively associated with information adoption. In other words, when an individual perceives information as being useful, that person is more likely to form the intention to adopt the information. 
Hypothesis 4a: In Thai consumers' opinions, information usefulness has an effect on the information adoption.

Hypothesis 4b: In Indonesian consumers' opinions, information usefulness has an effect on the information adoption.

\subsection{Online Information Adoption}

Similar to information usefulness, online information adoption serves two functions in this study. During the first stage, it serves as a dependent variable, which is affected by information usefulness. In the second stage, the variable serves as an independent variable that has an influence on consumers' purchasing intentions. Erkan and Evans [3] have linked the Information Adoption Model and Theory of Reasoned Action together to create the Information Acceptance Model, explaining that the purchase intentions of consumers may be influenced by online information adoption.

Hypothesis 5a: In Thai consumers' opinions, information adoption has an effect on purchase intentions.

Hypothesis 5b: In Indonesian consumers' opinions, information adoption has an effect on purchase intentions.

\section{Methodology}

\section{1 samples and data collection}

The study populations are Thai and Indonesian millennials (between 17 - 39 years old) that are exposed to the internet, regardless of the platform used. Based on 95\% confidence level of Yamane's Formula, the expected sample size is 400 respondents. Using the quota technique, the authors divided the samples into two halves; 200 Thai and 200 Indonesian respondents. The samples were randomly collected online, from August to December 2018, from the target population, with different backgrounds, including gender, age, and internet familiarity.

Descriptive statistics of samples on demographic data are shown in Table 1. To sum up, both groups can be considered active and are familiar with the internet, as the majority of the respondents use the internet for more than 5 hours a day, and a majority of them have been using the internet for more than 6 years. In terms of the platform, Youtube is the most popular social networking site for Thai respondents, while almost of all Indonesian respondents are registered on Instagram.

\section{2 research instrument and variable measurement}

The research instrument was a questionnaire comprised of a total of 15 main questions to measure quantitative data. A screening question was set as the first question in the questionnaire to confirm that each respondent has experiences in using internet and social media. The questionnaire was divided into three sections; respondents' demographic profiles, their behavior with regards to the internet, and the respondents' opinions towards online information. The construction of consumers' 
opinions was measured with the five-point Likert scale, with 1 being strongly disagree and 5 being strongly agree. A sample of the questionnaire is provided in Appendix 1 . 
Table 1. Demographic Profile

\begin{tabular}{|c|c|c|c|c|}
\hline \multirow[t]{2}{*}{ Demographic Profile } & \multicolumn{2}{|c|}{ Thailand } & \multicolumn{2}{|c|}{ Indonesia } \\
\hline & No. & percentage & No. & percentage \\
\hline \multicolumn{5}{|l|}{ Gender } \\
\hline Male & 64 & $32.0 \%$ & 99 & $49.5 \%$ \\
\hline Female & 136 & $68.0 \%$ & 101 & $50.5 \%$ \\
\hline \multicolumn{5}{|l|}{ Internet Usage per day } \\
\hline Less than 60 minutes & 3 & $1.5 \%$ & 6 & $3.0 \%$ \\
\hline Between $1-3$ hours & 24 & $12.0 \%$ & 37 & $18.5 \%$ \\
\hline Between $3-5$ hours & 61 & $30.5 \%$ & 52 & $26.0 \%$ \\
\hline More than 5 hours & 112 & $56.0 \%$ & 105 & $52.5 \%$ \\
\hline \multicolumn{5}{|l|}{ Internet Familiarity } \\
\hline Less than 1 year & 1 & $0.5 \%$ & 1 & $0.5 \%$ \\
\hline Between $1-3$ years & 3 & $1.5 \%$ & 12 & $6.0 \%$ \\
\hline Between $3-6$ years & 32 & $16.0 \%$ & 42 & $21 \%$ \\
\hline More than 6 years & 164 & $82.0 \%$ & 145 & $72.5 \%$ \\
\hline \multicolumn{5}{|l|}{ Social Media Usage } \\
\hline Facebook & 146 & $73.0 \%$ & 74 & $37.0 \%$ \\
\hline Twitter & 149 & $74.5 \%$ & 41 & $20.5 \%$ \\
\hline Instagram & 159 & $79.5 \%$ & 194 & $97.0 \%$ \\
\hline Youtube & 178 & $89.0 \%$ & 163 & $81.5 \%$ \\
\hline Local website & 70 & $35.0 \%$ & 49 & $24.5 \%$ \\
\hline
\end{tabular}

\subsection{Reliability}

Cronbach's Alpha was used to perform reliability analysis to check the internal consistency of the variables. A pilot test of 30 respondents was performed. The preliminary results indicated that the Cronbach's alpha values of all variables were above 0.7. Then the researchers proceed collecting data from 400 respondents. The results, as shown in Table 2, suggest that the tested survey has acceptable internal consistency.

\subsection{Validity}

Factor analysis with varimax rotation was applied to test the validity of the constructs. As suggested by Hair et al. [27], the cut-off of factor loading was set at 0.50 . The results in Table 3 confirm that each of these constructs is in line with the constraint, each has factorial distinction, and that all items are loaded onto a single factor. 
Table 2. Internal Reliability of Variables

\begin{tabular}{|c|c|c|}
\hline \multirow{2}{*}{ Variable } & Thai & Indonesian \\
\hline & Cronbach's Alpha & Cronbach's Alpha \\
\hline Online Information Quality & 0.704 & 0.673 \\
\hline Online Information Credibility & 0.836 & 0.834 \\
\hline Attitude towards Online Information & 0.856 & 0.852 \\
\hline Online Information Usefulness & 0.740 & 0.710 \\
\hline Online Information Adoption & 0.774 & 0.744 \\
\hline Purchase Intention & 0.685 & 0.753 \\
\hline
\end{tabular}

Table 3. Factor Analysis

\begin{tabular}{lrcrr}
\hline \multicolumn{1}{c}{ Construct } & $\begin{array}{c}\text { No. of } \\
\text { items }\end{array}$ & $\begin{array}{c}\text { Factor } \\
\text { loading }\end{array}$ & Eigenvalues & $\begin{array}{c}\text { \% of } \\
\text { Variance }\end{array}$ \\
\hline Information Quality & 3 & $0.768-0.711$ & 3.145 & $28.594 \%$ \\
\hline Information Credibility & 3 & $0.844-0.826$ & 2.328 & $21.167 \%$ \\
\hline Attitude towards Information & 5 & $0.813-0.771$ & 1.889 & $17.172 \%$ \\
\hline
\end{tabular}

\section{Data Analysis}

\subsection{T-Test Analysis}

T-test analysis was conducted to determine significant differences between the mean scores of Thai and Indonesian respondents. As displayed in Table 4, the p-values of Online Information Quality, Online Information Credibility, and Purchase Intention are below 0.05, suggesting significant differences between the means, whereas the scores on Attitude towards Online Information, Online Information Usefulness, and Online Information Adoption suggest that the two countries are not significantly different in these regards.

\subsection{Correlation Analysis}

Correlation analysis was brought into play in order to test the degree of linear relationship between two variables, shown in Table 5 and 6 . Some correlations among independent variables are close to 0.6 which may lead to the multi-collinearity problem. Therefore the multi-collinearity diagnostic tests were performed.

\subsection{Collinearity Diagnostic Tests}

To further test for multi-collinearity issues, a problem occurs when there is a strong correlation among the variables, a collinearity diagnostic tests was conducted. O' Brien [28] has suggested that a tolerance score less than 0.2, as well as a VIF with a value greater than 5 , indicates a multi-collinearity problem. 
The results in Table 7 show that there is no multi-collinearity problem among the variables and confirms the validation of both samples.

Table 4. Independent T-Test

\begin{tabular}{|c|c|c|c|c|c|c|c|}
\hline & $\mathrm{F}$ & Sig. & $\mathrm{t}$ & df & $\begin{array}{c}\text { Sig. } \\
\text { (2-tailed) }\end{array}$ & $\begin{array}{c}\text { Mean } \\
\text { Difference }\end{array}$ & $\begin{array}{l}\text { Std. Error } \\
\text { Difference }\end{array}$ \\
\hline \multirow[t]{2}{*}{ OIQ } & 0.609 & 0.436 & -6.286 & 398 & 0.000 & -0.340 & 0.054 \\
\hline & & & -6.286 & 393.960 & 0.000 & -0.340 & 0.054 \\
\hline \multirow[t]{2}{*}{ OIC } & 12.632 & 0.000 & -5.829 & 398 & 0.000 & -0.373 & 0.064 \\
\hline & & & -5.829 & 388.853 & 0.000 & -0.373 & 0.064 \\
\hline \multirow[t]{2}{*}{ ATI } & 4.143 & 0.042 & 0.776 & 398 & 0.438 & 0.042 & 0.054 \\
\hline & & & 0.776 & 393.811 & 0.438 & 0.042 & 0.054 \\
\hline \multirow[t]{2}{*}{ OIU } & 1.246 & 0.265 & 1.005 & 398 & 0.316 & 0.053 & 0.052 \\
\hline & & & 1.005 & 397.996 & 0.316 & 0.053 & 0.052 \\
\hline \multirow[t]{2}{*}{ OIA } & 0.004 & 0.951 & 1.589 & 398 & 0.113 & 0.083 & 0.052 \\
\hline & & & 1.589 & 397.895 & 0.113 & 0.083 & 0.052 \\
\hline \multirow[t]{2}{*}{ PI } & 1.195 & 0.275 & -5.275 & 398 & 0.000 & -0.265 & 0.050 \\
\hline & & & -5.275 & 397.457 & 0.000 & -0.265 & 0.050 \\
\hline
\end{tabular}

Note: $O I Q=$ Online Information Quality, OIC = Online Information Credibility, ATI

$=$ Attitudes towards Online Information, OIU = Online Information Usefulness, OIA

= Online Information Adoption, PI = Purchase Intention

Table 5. Summary of Correlation among four variables on Thai respondents

\begin{tabular}{llllll}
\hline \multicolumn{1}{c}{ Variables } & \multicolumn{1}{c}{ OIQ } & OIC & ATI & OIU \\
\hline Online Information Quality & 1 & & & & \\
Online Information Credibility & $0.576^{*}$ & 1 & & & \\
Attitude towards Online Information & $0.234^{*}$ & $0.211^{*}$ & 1 & & \\
Online Information Usefulness & $0.130^{*}$ & $0.139 *$ & $0.594^{*}$ & 1 & \\
\hline
\end{tabular}

Note: $O I Q=$ Online Information Quality, OIC = Online Information Credibility, ATI $=$ Attitudes towards Online Information, OIU = Online Information Usefulness

*Significant level of 0.05

Table 6. Summary of Correlation among four variables on Indonesian respondents

\begin{tabular}{lllll}
\hline Variables & OIQ & OIC & ATI & OIU \\
\hline Online Information Quality & 1 & & & \\
Online Information Credibility & $0.487^{*}$ & 1 & & \\
Attitude towards Online Information & $0.301^{*}$ & $0.169 *$ & 1 & \\
Online Information Usefulness & $0.261^{*}$ & $0.299^{*}$ & $0.612^{*}$ & 1 \\
\hline
\end{tabular}

Note: $O I Q=$ Online Information Quality, OIC = Online Information Credibility, ATI

= Attitudes towards Online Information, OIU = Online Information Usefulness

*Significant level of 0.05 
Table 7. Collinearity statistics of three variables

\begin{tabular}{lcc}
\hline \multirow{2}{*}{ Variable } & \multicolumn{1}{c}{ Thai } & Indonesian \\
\cline { 2 - 3 } & Collinearity Statistics & Collinearity Statistics \\
\cline { 2 - 3 } & VIF & VIF \\
\hline Online Information Quality & 1.526 & 1.402 \\
Online Information Credibility & 1.509 & 1.312 \\
Attitude towards Online Information & 1.068 & 1.101 \\
\hline
\end{tabular}

\subsection{Stepwise Multiple Regression Analysis and Hypothesis Testing}

A stepwise multiple regression analysis was performed to identify the influence of the variables towards online information usefulness.

According to Table 8, only one variable appears to have an impact on Online Information Usefulness for Thailand, which is Attitudes towards Information $(\beta=$ $0.594, \mathrm{p}=0.000$ ). The adjusted $\mathrm{R} 2$ at 0.350 indicates that the predictor can explain $35 \%$ of the variance of Online Information Usefulness.

Table 8. Stepwise Multiple Regression for Thai respondents

\begin{tabular}{lcccccccccc}
\hline & Variable & $\mathrm{B}$ & $\beta$ & $\mathrm{t}$ & $\mathrm{Sig}$ & $\mathrm{R}$ & $\mathrm{R}^{2}$ & $\begin{array}{c}\text { Adj. } \\
\mathrm{R}^{2}\end{array}$ & $\begin{array}{c}\text { Overall } \\
\mathrm{F}\end{array}$ \\
\hline Criterion & OIU & & & & & 0.594 & 0.353 & 0.350 & 108.149 \\
Predictor & ATI & 0.547 & 0.594 & 10.399 & 0 & & & & \\
\hline
\end{tabular}

Note: $O I U=$ Online Information Usefulness, ATI = Attitudes towards Online Information

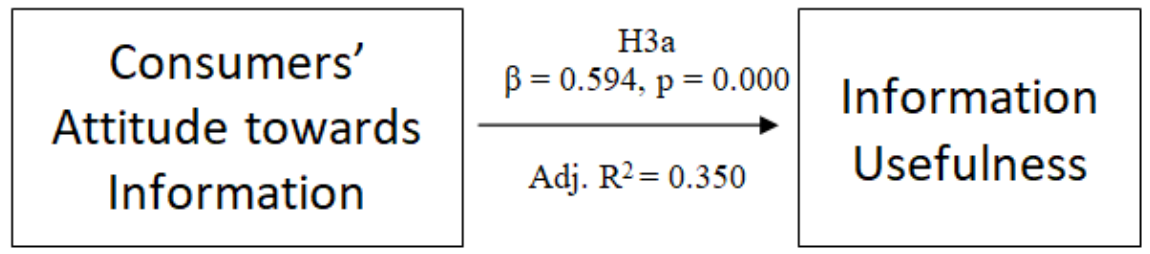

Fig. 2. Multiple Regression of Thai respondents

In Table 9, two variables appear to have an impact on Online Information Usefulness for Indonesia, which are Online Information Credibility $(\beta=0.201, p=$ $0.000)$, and Attitudes towards Information $(\beta=0.578, p=0.000)$. The adjusted $R 2$ at 0.408 indicates that the predictor can explain $40.8 \%$ of the variance of Online Information Usefulness. 
Table 9. Stepwise Multiple Regression for Indonesian respondents

\begin{tabular}{llccccccccc}
\hline & Variable & $\mathrm{B}$ & $\beta$ & $\mathrm{t}$ & $\mathrm{Sig}$ & $\mathrm{R}$ & $\mathrm{R}^{2}$ & $\begin{array}{c}\text { Adj. } \\
\mathrm{R}^{2}\end{array}$ & $\begin{array}{c}\text { Overall } \\
\mathrm{F}\end{array}$ \\
\hline Criterion & OIU & & & & & 0.644 & 0.414 & 0.408 & 69.640 \\
\hline \multirow{2}{*}{ Predictor } & OIC & 0.152 & 0.201 & 3.630 & 0 & & & & \\
& ATI & 0.589 & 0.578 & 10.455 & 0 & & & & \\
\hline
\end{tabular}

Note: $O I U$ = Online Information Usefulness, OIC = Online Information Credibility, ATI = Attitudes towards Online Information

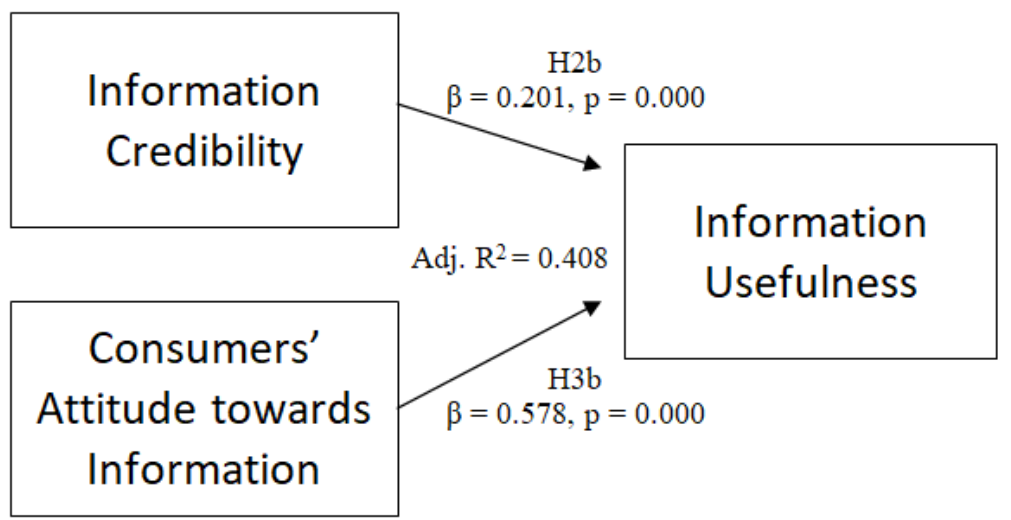

Fig. 3. Multiple Regression of Indonesian respondents

These experiments indicate that, for Thai respondents, only hypothesis $3 \mathrm{a}$ is supported. The second major finding is that, for Indonesian respondents, hypotheses $2 \mathrm{~b}$ and $3 \mathrm{~b}$ are supported. These results led to a further diagnosis on consumers' information adoption and purchase intentions.

\subsection{Online information Adoption Diagnosis}

To further analyze hypotheses H4a, H4b, H5a, and H5b, Pearson's Correlation Analysis was performed.

For Thai respondents, the statistics in Table 10 show that the variable (Online Information Usefulness) explained $24 \%$ of the variance of Online Information Adoption $(\mathrm{F}=64.282$, adjusted $\mathrm{R} 2=0.241)$. It shows that, if a consumer perceives an eWOM as being useful, they will probably adopt the information for further use.

In terms of Purchase Intention, Table 11 indicates that Online Information Adoption explained only $20.5 \%$ of the variance of Purchase Intention ( $F=52.280$, adjusted $\mathrm{R} 2=0.205$ ), suggesting that there is no strong relation between adoption and purchase intention. 
Table 10. Results indicating correlation between Online Information Usefulness and Online Information Adoption: Thai respondents

\begin{tabular}{lll}
\hline \multicolumn{1}{c}{ Variable } & & Online Information Adoption \\
\hline Online Information & Pearson & $0.495^{* *}$ \\
Usefulness & Correlation & \\
& Sig. & 0.000 \\
& Adjusted $\mathrm{R}^{2}$ & 0.241 \\
& Overall F & 64.282 \\
\hline
\end{tabular}

Table 11. Results indicating correlation between Online Information Adoption and Purchase Intention: Thai respondents

\begin{tabular}{lll}
\hline \multicolumn{1}{c}{ Variable } & \multicolumn{1}{c}{ Purchase Intention } \\
\hline Online Information Adoption & Pearson & $0.457^{* *}$ \\
& Correlation & 0.000 \\
& Sig. & 0.205 \\
& Adjusted $\mathrm{R}^{2}$ & 02.280 \\
\hline
\end{tabular}

For Indonesian respondents, the statistics in Table 12 show that the variable explained $26.2 \%$ of the variance of Online Information Adoption $(F=71.774$, adjusted $\mathrm{R} 2=0.262$ ), meaning that, if a consumer perceives an eWOM as being useful, that consumer will probably adopt the information for further use.

Table 12. Results indicating correlation between Online Information Usefulness and Online Information Adoption: Indonesian respondents

\begin{tabular}{cll}
\hline Variable & & Online Information Adoption \\
\hline Online Information Usefulness & Pearson & $0.516^{* *}$ \\
& Correlation & \\
& Sig. & 0.000 \\
& Adjusted $\mathrm{R}^{2}$ & 0.262 \\
& Overall $\mathrm{F}$ & 71.774 \\
\hline
\end{tabular}

In terms of Purchase Intention, Table 13 indicates that Online Information Adoption explained only $22 \%$ of the variance of Purchase Intention $(\mathrm{F}=57.541$, adjusted $\mathrm{R} 2=0.221$ ), indicating that there is no strong relation between adoption and purchase intention. 
Table 13. Results indicating correlation between Online Information Adoption and Purchase Intention: Indonesian respondents

\begin{tabular}{cll}
\hline Variable & & Purchase Intention \\
\hline \multirow{2}{*}{ Online Information Adoption } & Pearson & $0.475^{* *}$ \\
& Correlation & \\
& Sig. & 0.000 \\
& Adjusted $\mathrm{R}^{2}$ & 0.221 \\
& Overall $\mathrm{F}$ & 57.541 \\
\hline
\end{tabular}

To conclude, the results of the hypothesis testing show that hypotheses $\mathrm{H} 2 \mathrm{~b}, \mathrm{H} 3 \mathrm{a}$, $\mathrm{H} 3 \mathrm{~b}, \mathrm{H} 4 \mathrm{a}, \mathrm{H} 4 \mathrm{~b}, \mathrm{H} 5 \mathrm{a}$, and H5b are supported, as displayed in Figure 4 and Figure 5 as follows.

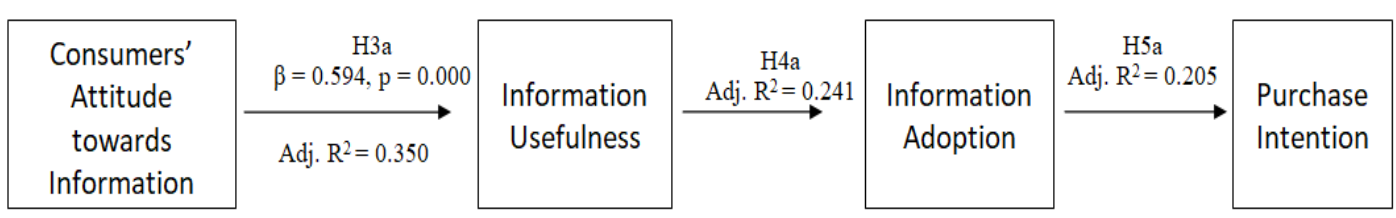

Fig. 4. Results of hypothesis testing of Thai respondents

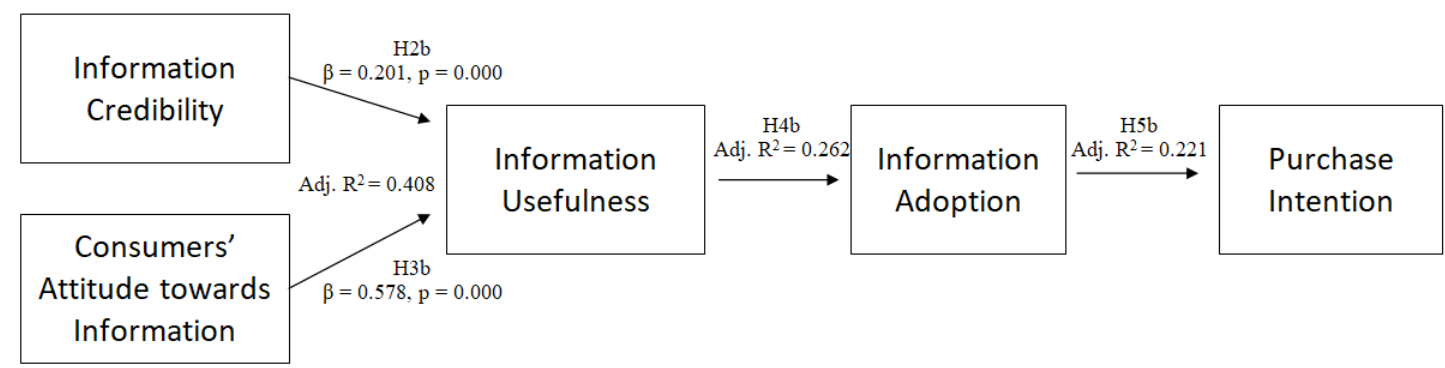

Fig. 5. Results of hypothesis testing of Indonesian respondents

\section{Conclusion and Discussion}

The main goal of the current study was to assess the influence of eWOM on Thai and Indonesian consumers' purchasing behavior, and determine if any cultural differences have an impact on the outcome. The study has identified that there are some similarities and distinctions between Thai and Indonesian consumers, and in how they perceive eWOM. In terms of similarities, the study indicates that consumers' Attitudes towards Online Information have a major impact on the perception of both groups towards the information's usefulness, while the quality of the information didn't have a significant influence on consumers' attitudes towards the usefulness of the information. Each consumer might focus on different factors when evaluating the quality of an information. Thus, the variable didn't show a significant influence on the consumers. 
Furthermore, the results showed a weak-to-moderate connection between online information usefulness and information adoption, as well as information adoption and consumers' purchasing intentions. This may mean that the consumers are most likely to focus more on their needs and their opinions towards a product or service, rather than leaning completely on available online information. The parallel results could also be on account of the cultural aspects. Living in Southeast Asian countries, the people of Thailand and Indonesia tend to be more collective in their thinking and dependent on hierarchy, in which individuals are likely to conform to expectations, such as being part of a group or being non-confrontational, while being respectful towards their superiors, and avoiding any acts that might lead to loss of face. These characteristics could probably be used to help interpret the weak-to-moderate connection between variables, as information or opinions of an individual person in a consumer's group could be more influential than online information from an unknown person.

However, Online Information Credibility is a significant factor whose effect was identified as being different when it comes to Thai and Indonesian consumers, as it is regarded as a meaningful factor for Indonesian consumers, while being disregarded by Thai consumers. Once again, a probable interpretation based on cultural aspects could be brought in to explain the result. According to Hofstede's model, Thai society leans towards being a short-term oriented country, while Indonesia is seen as being long-term oriented. Thai society is more normative and more focused on quick results, whereas Indonesian society is more pragmatic, and prepares for the future. This characteristic of Indonesian culture could provide and explanation to the question of why Indonesian respondents also focus on the source credibility before determining its usefulness.

Although there is only a weak-to-moderate connection between Online Information Usefulness and Online Information Adoption, and between Online Information Adoption and Purchase Intention, as there are other external factors that could influence the consumers to make or not to make a purchase, the authors believe that the results of this study would still be useful in developing Word-of-Mouth marketing strategies to increase sales. The eWOM could be a method to gain consumers' trust and loyalty in a way that an advertisement is unable to do in a more cost-effective way. The use of an amplified Word of Mouth via the internet could spark consumers' interest over a product or service, and create a buzz within no time. However, the marketers should be aware that too much effort of an amplified Word of Mouth could be regarded as an infomercial that could backfire. Thus, a business using such strategy should focus on the quality of the product or the service itself, as well as consumers' experience in order to build a long-term brand loyalty.

Clearly, there is room within the research for future research and study. The authors focused on millennials, as they have been exposed to the internet from their earliest youth. Yet, the research didn't investigate association related to age diversity. Comparing younger and older generations could be an interesting aspect to explore in future research; it could be enlightening to learn if age or internet familiarity play any role in consumers' online information adoption or other stages of purchase. Further research and experimentation would also be of great help in determining if different sources of information, in terms of both the identity of the information provider and on which platform is the information is published, has an effect on consumers' trust. More broadly, the association between different types of products and services has not 
been subject to sufficient study. Further research might explore if eWOM has a stronger impact on specific products or services.

\section{APPENDIX A. QUESTIONNAIRE}

Answer the following questions from $1=$ strongly disagree to $5=$ strongly agree .

\section{Online information Quality}

1. The information is clear

2. The information is understandable.

3. The information is relevant to the topic.

\section{Online information Credibility}

1. The information is credible.

2. The information is accurate.

3. The source of the information is trustworthy.

\section{Consumers' Attitudes towards Online Information}

1. I like to apply the knowledge I gained from the internet when I consider new products.

2. If I have little experience with a product, I often use information from the internet.

3. I always read online information when I buy any product or service.

4. Online information is helpful for my decision making when I buy a product or service.

5. Online information makes me confident in purchasing a product.

Online Information Usefulness

1. I think they are generally useful.

2. I think they are generally informative.

\section{Online Information Adoption}

1. Online information makes it easier for me to make purchase decision.

2. Online information enhances my effectiveness in making purchase decision.

3. I usually apply my previous knowledge to what I have read online.

Purchase Intention 
1. After I read online information, it is very likely that I will buy the product or service.

2. I will definitely try the product.

3. I will purchase the product or service next time I need it.

4. I will recommend the product to my friends and family.

\section{REFERENCES}

[1] Online Feedback Significantly Influences Consumer Purchasing Decisions, Opinion Research Corporation Study Finds, 2009. Retrieved September 4, 2018, from

https://www.businesswire.com/news/home/20090415005155/en/Online-Feedbac k-Significantly-Influences-Consumer-Purchasing- Decisions.

[2] S. C. Chu and Y. Kim, Determinants of consumer engagement in electronic word-of-mouth (eWOM) in social networking sites. International Journal of Advertising (30), 47-75, 2015.

[3] I. Erkan, and C. Evans, The influence of eWOM in social media on consumers' purchase intentions: An extended approach to information adoption. Computers in human behavior, 61, 47-55, 2016.

[4] J. F. Engel, R. J. Kegerreis, and R. D. Blackwell, Word-of-mouth Communication by the Innovator. Journal of Marketing, 33(3), 15-19, 1967.

[5] M. L. Richins, and T. Root-Shaffer, The Role of Evolvement and Opinion Leadership in Consumer Word-Of-Mouth: an Implicit Model Made Explicit. Advances in Consumer Research, 15, 32-36, 1988.

[6] F. F. Reichheld, The One Number You Need to Grow. Harvard Business Review, 2003.

[7] P. M. Herr, F. R. Kardes, and J. Kim, Effects of Word-of-Mouth and Product-Attribute Information on Persuasion: An Accessibility-Diagnosticity Perspective. Journal of Consumer Research, 17(4), 454-462, 1991.

[8] M. M. Almossawi, The Impact of Word of Mouth (WOM) on the Bank Selection Decision of the Youth: A Case of Bahrain. International Journal of Business and Management, 10(4), 123-135, 2015.

[9] K. H. Hung, and S. Y. Li, The Influence of eWOM on Virtual Consumer Communities: Social Capital, Consumer Learning, and Behavioral Outcomes. Journal of Advertising Research, 47 (4), 485-495, 2007.

[10] T. Hennig-Thurau, K. P. Gwinner, G. Walsh, and D. D. Gremler, Electronic word-of-mouth via consumer-opinion platforms: What motivates consumers to articulate themselves on the Internet? Journal of Interactive Marketing, 18(1), 38-52, 2004.

[11] R. Y. Wang, and D. M. Strong, Beyond accuracy: what data quality means to data consumers. Journal of Management Information Systems, 12(4), 5-34, 1996.

[12] J. Kandari, E. C. Jones, F. F. Nah, and R. Bishu, Information quality on the World Wide Web: Development of a framework. International Journal of Information Quality 2(4), 324-343, 2011.

[13] M. Hogg, and G. Vaughan, Social psychology. New York: Prentice Hall, 2005.

[14] L. G. Schiffman, and L. L. Kanuk, Consumer behavior. Upper Saddle River, NJ: Pearson Prentice Hall, 2004. 
[15] V. Jain, 3D Model of Attitude. International Journal of Advanced Research in Management and Social Sciences 3(3), 1-12, 2014.

[16] W. Kenton, Bandwagon Effect. Retrieved September, 21, 2018 from https://www.investopedia.com/terms/b/bandwagon-effect.asp.

[17] M. C. Munthiu, The buying decision process and types of buying decision behavior. Sibiu Alma Mater University Journals. Series A. Economic Sciences, 2(4), 27-33, 2009.

[18] L. Xiao. F. Guo, F. Yu, and S. Liu, The Effects of Online Shopping Context Cues on Consumers' Purchase Intention for Cross-Border E-Commerce Sustainability. Sustainability, 11(10), 2777, 2019.

[19] M. Poturak, and S. Softic, Influence of Social Media Content on Consumer Purchase Intention: Mediation Effect of Brand Equity. Eurasian Journal of Business and Economics, 12(23), 17-43, 2019.

[20] G. Hofstede, Dimensionalizing Cultures: The Hofstede Model in Context. Retrieved August, 31, 2018 from https://scholarworks.gvsu.edu/orpc/vol2/iss1/

[21] Hofstede's Cultural Dimensions. Retrieved January, 08, 2019 from https://www.hofstede-insights.com/

[22] I. Han, J. Lee, and D. Park, The Effect of On-Line Consumer Reviews on Consumer Purchasing Intention: The Moderating Role of Involvement. International Journal of Electronic Commerce, 11, 125-148, 2007.

[23] E. Lee, and S. Shin, When do consumers buy online product reviews? Effects of review quality, product type, and reviewer's photo. Computers in human behavior, 31, 356-366. 2013.

[24] D. Ko, G. Prendergast, and G. V.Y.S. Yin, Online word of mouth and consumer purchase intentions. International Journal of Advertising, 29, 687-708, 2010.

[25] M. Fishbein, and I. Ajzen, Belief, Attitude, Intention, and Behavior: An Introduction to Theory and Research. Reading, MA: Adison-Wesley. 1975. Retrieved September, 26, from https://people.umass.edu/ aizen/f\&a1975.html

[26] S. W. Sussman, and W. Siegal, Informational Influence in Organizations: An Integrated Approach to Knowledge Adoption. Information Systems Research, 14, 47-65. 2003.

[27] J. Hair, W. Black, B. Babin, R. Anderson, and R. Tatham, Multivariate DataAnalysis. Prentice Hall, Upper Saddle River, 2006.

[28] O'brien, R.M., A Caution Regarding Rules of Thumb for Variance Inflation Factors. Quality \& Quantity, 41(5), 673-690, 2007. 